\title{
Tissue-engineered stent-graft integrates with aortic wall by recruiting host tissue into graft scaffold
}

\author{
Mugiho Takeuchi, MD, ${ }^{\text {a }}$ Toru Kuratani, MD, PhD, ${ }^{\text {a }}$ Shigeru Miyagawa, MD, PhD, ${ }^{\text {a }}$ \\ Yukitoshi Shirakawa, MD, PhD, ${ }^{\mathrm{a}}$ Kazuo Shimamura, MD, ${ }^{\mathrm{b}}$ Keiwa Kin, MD, ${ }^{\mathrm{b}}$ Takuya Yoshida, MD, \\ Yoshio Arai, MD, PhD, ${ }^{\mathrm{c}}$ Takaya Hoashi, MD,${ }^{\mathrm{d}}$ Noboru Teramoto, PhD, ${ }^{\mathrm{d}}$ Koichiro Hirakawa, MS, \\ Naomasa Kawaguchi, $\mathrm{PhD},{ }^{f}$ and Yoshiki Sawa, $\mathrm{MD}, \mathrm{PhD}^{\mathrm{a}}$
}

\begin{abstract}
Objective: To prevent postoperative migration and endoleaks after endovascular aneurysm repair, we developed a tissue-engineered vascular graft that integrates with the aortic wall by recruiting the host tissue into the graft scaffold. In the present study, we assessed the mechanical properties of the new graft and evaluated the integration between the graft and aortic wall histologically and mechanically in canine models.
\end{abstract}

\begin{abstract}
Methods: The tissue-engineered vascular graft was woven to be partially degradable with a double-layered fiber (core; polyethylene terephthalate [PET], and sheath; polyglycolic acid [PGA]). The mechanical properties of the graft were assessed compared with a thin-walled woven polyester graft (control; $12 \mathrm{~mm}$ in diameter, $30 \mathrm{~mm}$ long). The stent-grafts, composed of a stainless $\mathrm{Z}$ stent $(20 \mathrm{~mm}$ in diameter, $25 \mathrm{~mm}$ long) and a PET/PGA or control graft ( $\mathrm{n}=5$ in each group), were implanted in the descending thoracic aorta of mongrel dogs for 2 months. We assessed the histologic findings of the explants and the degree of adhesion between the graft and aortic wall.

Results: The PET/PGA graft achieved nearly the same mechanical properties as those of the control graft in tensile strength and flexibility, with slightly greater water permeability. At 2 months after implantation, in the PET/PGA group, the PGA component had degraded and been replaced by host tissue that contained a mixture of $\alpha$-smooth muscle actin-positive cells and other host cells. The graft was a unified structure with the aorta. The adhesion strength between the graft and aortic wall was significantly enhanced in the PET/PGA group.
\end{abstract}

Conclusions: The PET/PGA stent-graft demonstrated histologic and mechanical integration with the native aorta. This next-generation stent-graft might reduce the risk of migration and endoleaks, leading to preferable long-term results of endovascular aneurysm repair. (J Thorac Cardiovasc Surg 2014;148:1719-25)

Endovascular aneurysm repair (EVAR) for various aortic diseases has become widespread as a less invasive alternative to conventional open surgery. Randomized trials have shown lower perioperative and early postoperative mortality and morbidity in favor of EVAR. ${ }^{1,2}$ However, these trials demonstrated that EVAR was associated with a significantly greater incidence of aortic complications and reintervention in the long term. Most of these postoperative adverse events were migrations of the stent-

\footnotetext{
From the Departments of Cardiovascular Surgery ${ }^{\mathrm{a}}$ and Advanced Cardiovascular Therapeutics, ${ }^{\text {b }}$ Osaka University Graduate School of Medicine, Osaka, Japan; Department of Vascular Surgery, ${ }^{\mathrm{c}}$ Kokura Memorial Hospital, Kitakyushu, Japan; Department of Cardiovascular Surgery, ${ }^{\mathrm{d}}$ National Cerebral and Cardiovascular Center, Osaka, Japan; Senko Medical Instrument Manufacturing Company, Limited, ${ }^{\mathrm{e}}$ Saitama, Japan; Department of Pathology, ${ }^{\mathrm{f}}$ Osaka University School of Allied Health Science, Osaka, Japan.

Disclosures: Authors have nothing to disclose with regard to commercial support.

Received for publication Sept 25, 2012; revisions received March 18, 2014; accepted for publication April 3, 2014.

Address for reprints: Yoshiki Sawa, MD, PhD, Department of Cardiovascular Surgery, Osaka University Graduate School of Medicine, 2-2 Yamadaoka, Suita, Osaka 565-0871, Japan (E-mail: sawa@surg1.med.osaka-u.ac.jp). $0022-5223 / \$ 36.00$

Copyright $(2014$ Published by Elsevier Inc. on behalf of The American Association for Thoracic Surgery

http://dx.doi.org/10.1016/j.jtcvs.2014.04.003
}

graft and endoleaks, ${ }^{1}$ which can occur even several years after the initial treatment with primary success and lead to an aneurysm rupture if untreated. ${ }^{3}$

One of the major causes of such late complications after EVAR has been attributed to poor tissue affinity of the implant, which results in a lack of biologic fixation between the graft and the native vascular wall., ${ }^{4,5}$

Currently, the fixation of the graft mainly depends on the radial force exerted by the stent or hooks and is not enough to prevent migrations or endoleaks. ${ }^{4,6}$ Regarding migration of the stent-graft, the reported incidence rate has ranged from approximately $2 \%$ to $20 \%{ }^{7-9}$

New generation stent-grafts that integrate with the host aorta and promote biologic fixation on the vascular wall, in addition to the mechanical fixation, can improve the postoperative course of EVAR dramatically.

In addition, tissue-engineered vascular grafts (TEVGs) using bioabsorbable materials have been enthusiastically developed to induce host tissues into the graft scaffold. ${ }^{10}$ We expected that TEVGs could be the material used in the new generation stent-grafts that would integrate with the native vascular wall by recruiting the host tissue into the graft scaffold and increase the adhesion force to the aortic wall. 


\section{Abbreviations and Acronyms \\ $\alpha$-SMA $=\alpha$-smooth muscle actin \\ EVAR $=$ endovascular aneurysm repair \\ PET = polyethylene terephthalate \\ PGA $=$ polyglycolic acid \\ TEVG $=$ tissue-engineered vascular graft}

In the present study, we invented a novel TEVG for EVAR and assessed whether the graft would be suitable as a graft material for a stent-graft and whether the graft would unify with the host aorta histologically and enhance fixation to the aortic wall.

\section{METHODS \\ Graft Design}

The new TEVG for EVAR was woven with a thread of polyethylene terephthalate (PET) fibers as the warp and a partially bioabsorbable double-layered yarn using polyglycolic acid (PGA) as a woof: PET/PGA graft (Figure 1, A). The core of the double-layered yarn was composed of 20 filaments of PET and 28 of PGA, and slack loops of the PGA filaments formed the outer sheath (Figure $1, B$ ). The estimated pore size of the graft after absorption of the PGA component was $255.7 \mu \mathrm{m}^{2}$. The graft was provided by Senko Medical Instrument Manufacturing Co, Ltd (Tokyo, Japan). All the materials had received Food and Drug Administration clearance.

\section{Product Test}

The mechanical properties of the PET/PGA graft were evaluated in comparison with a control graft (a thin-walled woven polyester graft; WST UBE, Ube Industries, Ltd, Tokyo, Japan). The product test was performed in accordance with the Food and Drug Administration guidelines for a vascular prosthesis (ANSI AAMI ISO 7198:2001, Cardiovascular implants, Tubular vascular prostheses).

Tensile strength. The tensile strength of each graft was evaluated using a tensile mechanical tester (IM-20DX, INTESCO Co, Chiba, Japan). Longitudinal strips $(25 \times 5 \mathrm{~mm})$ of the graft were placed in the tensile tester, and a traction force was applied. The maximum strength of the breaking point was measured.

Flexibility. The flexibility of the graft was evaluated by measuring the bending properties under pure bending conditions using KES-FB2-AUTOA (Kato Tech Co, Ltd, Kyoto, Japan). After mounting a specimen, a bending motion was performed automatically to measure stiffness and hysteresis.

Water permeability. The water permeability of the graft was calculated from the amount of water that transmitted through the graft under pressure of $120 \mathrm{~mm} \mathrm{Hg} / \mathrm{min} / \mathrm{cm}^{2}$.

Accelerated aging test. The durability of the graft was assessed in an accelerated aging test. A 30-mm-long PET/PGA graft was opened longitudinally, soaked in $150 \mathrm{~mL}$ of phosphate-buffered saline, and incubated at $55^{\circ} \mathrm{C}$ for $2,4,11,21,28$, and 55 days. Afterward, the tensile strength of each sample was evaluated with the tensile mechanical tester, as described.

\section{Implantation of Stent-Grafts}

The stent-grafts, using a PET/PGA graft or a thin-walled woven polyester graft ( $\mathrm{n}=5$ in each group), were implanted in the descending thoracic aorta of female mongrel dogs (weight, $18-22 \mathrm{~kg}$ ) for 2 months.

Fabrication of stent-graft. The stent-graft was composed of the graft (a PET/PGA or woven polyester graft; $12 \mathrm{~mm}$ in diameter and 30 $\mathrm{mm}$ long) and a self-expandable stainless Z stent (Gianturco Z; $20 \mathrm{~mm}$ in diameter and $25 \mathrm{~mm}$ long; William Cook Europe A/S, Bjaeverskov,
Denmark; Figure 1, A). The stent was attached inside the graft with 50 polypropylene sutures (Ethicon, Inc, Somerville, NJ).

Delivery system. The inner dilator of an $18 \mathrm{~F}$ Keller-Timmermann Introducer Sheath (Cook Medical, Inc, Bloomington, IN) was curved so that it could contain the stent-graft under the outer sheath (Figure 1, C). The sterilized stent-graft was packaged inside the sheath at the operation. Procedure. All the dogs were anesthetized by intramuscular injection of $10 \mathrm{mg} / \mathrm{kg}$ ketamine (Sankyo Co, Tokyo, Japan) and $2 \mathrm{mg} / \mathrm{kg}$ of xylazine (Bayer Medical Co, Tokyo, Japan) followed by intubation and mechanical ventilation. Propofol (AstraZeneca, Osaka, Japan) was continuously injected at a rate of $4 \mathrm{mg} / \mathrm{kg} / \mathrm{h}$ to maintain the appropriate level of anesthesia during the operation. Antibiotics were given intravenously before the skin incision.

The dog was placed in the right lateral decubitus position, and the descending thoracic aorta was carefully exposed through the left ninth intercostal space. Heparin (100 IU/kg) was administered intravenously. The delivery system was inserted into the thoracic aorta under direct vision and, after aortography, advanced proximally over a stiff guide wire under fluoroscopic guidance. The stent-graft was deployed at the proximal descending aorta. The delivery system and guide wire were removed, and hemostasis was confirmed. Protamine was administered intravenously, and the chest incision was closed. After completion of the surgical procedure, the dog was extubated and resumed normal activities. After 2 months, the dog was again anesthetized using the same protocol. Aortography was performed to assess luminal stenosis or migration of the stent-graft. The chest incision was reopened, and the dog was euthanized. The graft was carefully explanted with the adjacent aortic segment, examined macroscopically, and processed immediately with $10 \%$ buffered formalin for tissue assessment.

All dogs received humane care in compliance with the Principles of Laboratory Animal Care, formulated by the National Society for Medical Research, and the Guide for the Care and Use of Laboratory Animals, published by the National Academy of Science and National Institutes of Health (NIH Publication No. 86-23, revised 1996).

\section{Evaluation of Explanted Specimen}

Evaluation of adhesion strength. Longitudinal small sections of the whole layer of the explants were cut at the same size $(35 \times 5 \mathrm{~mm})$ after $10 \%$ buffered formalin fixation. Adhesion between the graft and the aortic wall of the piece was assessed by applying a traction force in the opposite direction along the long axis to each of the layers (the graft or native aorta) using a tensile mechanical tester (Tensilon RTC-1150A, Orientec Co, Tokyo, Japan). The ultimate load at which the graft detached from the aortic wall was recorded.

Histologic evaluation. All the explants (the segment of the aorta containing the stent-graft) were opened longitudinally and were examined macroscopically for neointimal formation, thrombus, and stenosis on the luminal side. They were then photographed and immediately fixed in $10 \%$ buffered formalin.

After removal of the metal frames of the stents, longitudinal sections of the explants were embedded in paraffin and examined by double staining with hematoxylin-eosin and Victoria blue for elastic fibers. Immunohistologic staining was performed using monoclonal antibodies against $\alpha$-smooth muscle actin ( $\alpha$-SMA; Dako Corp, Carpinteria, Calif) and a polyclonal antibody against von Willebrand factor (catalog no. N1505; Dako) for endothelial cells.

The number of cells migrating in each type of the graft $(n=5)$ was counted on 5 representative sections of each graft per $0.1-\mathrm{mm}$ square at $\times 400$ magnification with the aid of a microscope (BZ-9000; Keyence Corp, Osaka, Japan).

\section{Statistical Analysis}

All values are presented as the mean \pm standard deviation. A standard $t$ test was used to determine the significance of the difference between the 2 


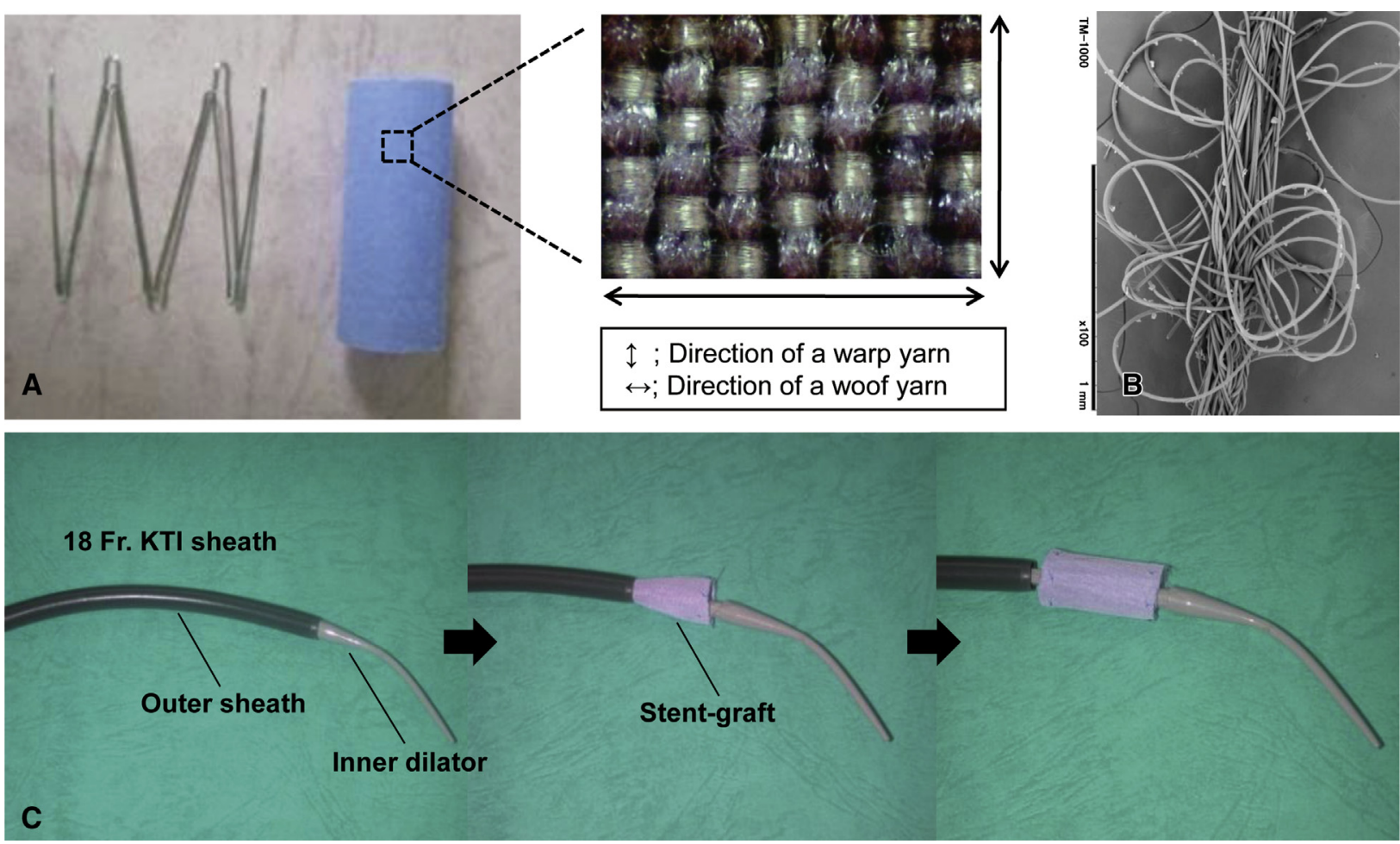

FIGURE 1. A, Composition of the new stent-graft using the polyethylene terephthalate (PET)/polyglycolic acid (PGA) graft and a self-expanding stainless $\mathrm{Z}$ stent. The PET/PGA graft was woven with a double-layered yarn compound with the PET and PGA filaments as the warp and a thread of PET fibers as the woof. B, High magnification of the double-layered warp yarn. The core of the yarn was composed of a mixture of PET and PGA filaments, and slack loops of the PGA filaments formed the outer sheath. C, Delivery system of the stent-graft. The inner dilator of the 18F Keller-Timmermann Introducer Sheath (KTI) (Cook Medical, Inc) was curved such that it could contain the stent-graft under the outer sheath.

mean values. The data were analyzed using StatView, version 5.0, for Windows (SAS Institute, Inc, Cary, NC).

\section{RESULTS \\ Product Test}

The product test of the PET/PGA showed satisfactory mechanical properties compared with the thin-walled woven polyester graft (Figure 2).

Tensile strength. The mean maximal longitudinal tensile strength of the PET/PGA and control grafts was $44.7 \pm$ $5.4 \mathrm{~N}$ and $52.6 \pm 8.0 \mathrm{~N}$, respectively ( $P=\mathrm{NS}$; Figure $2, A)$. Flexibility. The pure bending test revealed that the flexibilities of both types of grafts were less than the measurement limit, showing sufficient suppleness of the PET/PGA graft (Figure 2, B; PET/PGA vs woven polyester, $0.55 \pm 0.05$ vs $0.15 \pm 0.02 \mathrm{graft} / \mathrm{cm}^{2} / \mathrm{cm}$ ).

Water permeability. The water permeability of the PET/ PGA and control grafts was $151.6 \pm 6.3$ and $78.0 \pm 13.4$ $\mathrm{mL} / \mathrm{cm}^{2} / \mathrm{min} / 120 \mathrm{~mm} \mathrm{Hg}$, respectively $(P=.0005)$.

Accelerated aging test. Regarding durability, the accelerated aging test showed that the PET/PGA graft maintained its tensile strength throughout the observation period and did not weaken with time (Figure 2,D). The tensile strength of the PET/PGA graft at baseline and at the 37-, 97-, and 180-equivalent day period after incubation was $54.6 \pm$ $2.08,53.3 \pm 2.29,55.8 \pm 3.26$, and 54.6 \pm 2.08 , respectively.

\section{Implantation of Stent-Grafts}

All the operations were completed successfully. All the dogs survived without any postoperative complications during the predetermined observation period. Aortography just before the euthanasia revealed no apparent stenosis or migration of the stent-graft in either group.

\section{Evaluation of Explanted Specimen}

Evaluation of adhesion strength. In the PET/PGA group, the degree of the adhesion of the graft to the aortic wall was significantly increased compared with those in the control group. The maximum load at which the graft became detached from the aorta was $6.62 \pm 1.36 \mathrm{~N}$ in the PET/PGA group and $3.53 \pm 0.84$ in the control group $(P<.0001$; Figure 3).

Histologic evaluation. On gross inspection, the inner surface of all the grafts was covered with a uniformly smooth layer of neointima, except on some parts of the metal frame of the stents. No thrombus or stenosis was observed in the luminal side, regardless of the graft type (Figure 4). When 

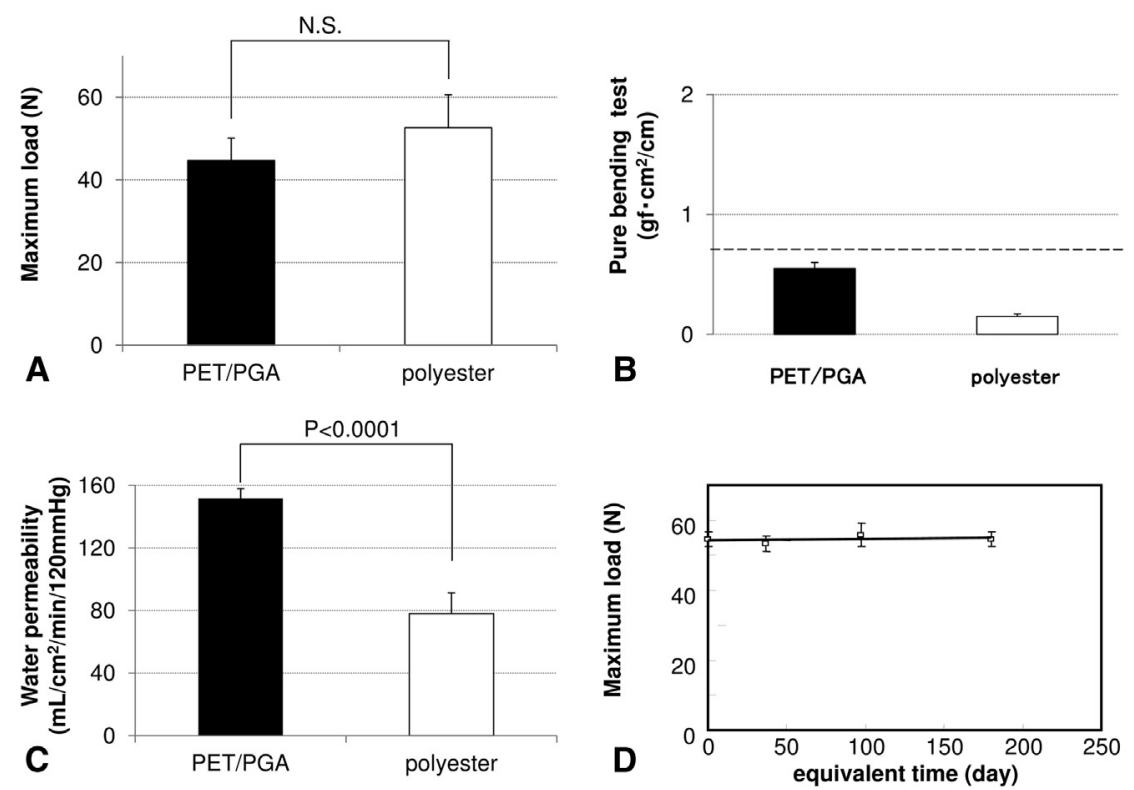

FIGURE 2. Comparative evaluation of the mechanical properties between the polyethylene terephthalate (PET)/polyglycolic acid (PGA) graft and a thinwalled woven polyester graft. A, Tensile strength. B, Water permeability. The dashed line indicates measurement sensitivity. C, Flexibility evaluated using the KES-FB2-AUTO-A (KES) (Kato Tech Co, Ltd) pure bending test. D, Assessment of the temporal durability of the PET/PGA graft using the accelerating aging test. N.S., Not significant.

the explants were cut into sections, the control grafts tended to detach easily from the aortic wall in contrast to the PET/ PGA grafts.

Microscopically, in the PET/PGA group, the PGA component had degraded and had been replaced by the host tissue (Figure 5, A, upper). The interstices at which the PGA had degraded contained a mixture of $\alpha$-SMA-positive cells and other host cells (Figure 5, B, left). Thus, the remaining PET fibers of the graft scaffold had been incorporated into the surrounding tissue of the vessel wall and had become unified with the native aortic wall. In contrast, in the control group, we observed very few host cells infiltrating into the graft (Figure 5, $A$, lower and $B$, right). Although the neointima had covered the graft surface, no histologic continuity was found between the woven polyester control graft and the native aorta.

In both groups, a von Willebrand factor-positive monolayer of endothelial cells was observed at the luminal surface (Figure 5, A, right). The monolayer had segued into the native endothelium at the edge of the graft. Beneath the endothelial layer, accumulated layers of $\alpha$-SMApositive cells that sandwiched the graft were observed (Figure 5, A, middle). This layer was rich in collagen and contained lots of microvessels. No regeneration of the elastic fibers in the layer had occurred (Figure 5, A, left). The thickness of this layer varied greatly by location, regardless of the graft type or graft side.

The number of cells migrating in the graft was significantly larger in the PET/PGA group (PET/PGA vs control woven polyester graft, $2613.3 \pm 286.3$ vs $455.6 \pm 78.0$ / $\mathrm{mm}^{2} ; P<.01$; Figure 5, C).

\section{DISCUSSION}

The present study incorporated a novel idea of using tissue-engineered biodegradable materials for EVAR to prevent migration by increasing the fixation force of the stentgraft after implantation. At present, the neoendothelium with the currently available vascular prosthesis is incomplete and fragile. ${ }^{4-6}$ Major and colleagues ${ }^{6}$ reported on the histologic features of 12 aortic stent-grafts composed of a polyester graft, explanted at autopsy or late surgical conversion to open repair, with an average implantation period of 28 months after EVAR. They found the luminal side of the explants was incompletely covered with a thin, fragile pseudo-neointimal layer that was unorganized thrombus mainly composed of fibrins and phantom red blood cells and lacked smooth muscle cells, fibroblasts, and collagen.

The incidence of migration after EVAR has been reported to range from $2 \%$ to $20 \%{ }^{7-9}$ Zarins and colleagues ${ }^{7}$ reported in a review of a multicenter, prospective, clinical trial that the freedom from migration was $98.6 \%$ at 1 year, $93.4 \%$ at 2 years, and $81.2 \%$ at 3 years. Although the rate of migration has decreased with device improvement, it is still concerning, especially when a patient has hostile neck anatomy. ${ }^{8}$

New generation stent-grafts that integrate with the host aorta and promote biologic fixation on the vascular wall, in addition to the mechanical fixation, might improve the postoperative course of EVAR dramatically ${ }^{6}$ and could 


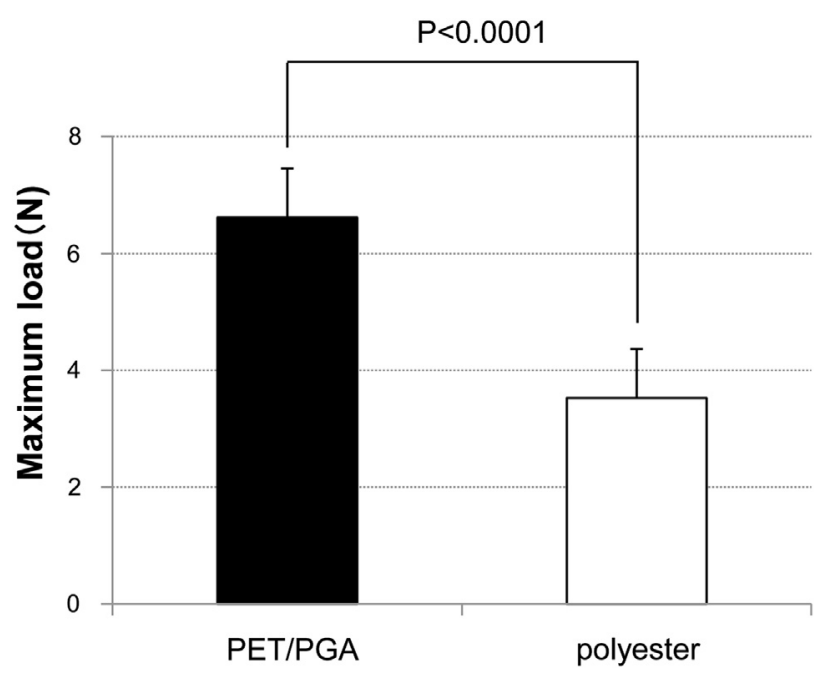

FIGURE 3. Evaluation of the adhesion strength between the 2 grafts and the native aortic wall at 2 months after implantation. PET/PGA, Polyethylene terephthalate/polyglycolic acid.

lead to expanded indications for those with challenging landing zones.

First, the present study has demonstrated that the TEVG could be an adequate graft material for EVAR. Second, the implantation study showed that the stent-graft using the TEVG promoted histologic integration with a native aortic wall by recruiting the host cells in situ without any preoperative pretreatment for the scaffold and that the fixation force of the graft to the aortic wall was significantly enhanced compared with the woven polyester graft.

Regarding the graft material for a next generation stentgraft, bioabsorbable TEVGs seem promising in that they have the potential to integrate with the native vascular wall. ${ }^{10}$ TEVGs, to date, however, are rather unsuitable as a material for a stent-graft because they usually require ex vivo pretreatment ${ }^{11}$ and lack flexibility. Furthermore, the graft must maintain its intensity after degradation to cover a fragile, diseased portion of the aorta with a degenerative aneurysm or an aortic dissection. Regarding the first problem, we had previously developed TEVGs that did not require ex vivo pretreatment such as cell seeding or culture. $^{12-14}$ These TEVGs, consisting of PGA and poly-Llactic acid, were able to reconstruct the vascular wall in situ by recruiting the host tissue into the graft scaffolds and were durable even under high systemic pressure in the long term. We applied these TEVGs to create the next generation stent-graft. Allowing for the second and third problems, the new graft was designed to be not completely bioabsorbable but only partially biodegradable using flexible materials. We fabricated the core-sheath structured tissue-engineered yarn by compounding degradable PGA fibers and nondegradable PET fibers currently used as vascular prosthetic materials. Additionally, to make the new graft as flexible as the current vascular prostheses, we used the 2-layered yarn only for a woof to weave the PET/PGA graft. Thus, the newly invented PET/PGA graft had tensile strength and flexibility comparable to that of the current woven polyester graft and demonstrated longterm durability even after the PGA component had degraded. This result suggested that the tensile strength of the PET/PGA graft was mainly attributable to the nonabsorbable PET component and that the graft would retain sufficient intensity in the long term to exclude the fragile, diseased area of the aorta, even after degradation of the PGA component.

Although the water permeability was slightly greater in the PET/PGA graft, the high porosity could be advantageous for tissue regeneration on the graft scaffold. ${ }^{15} \mathrm{We}$ have assumed that after the host tissue has clogged the interstices of the scaffold, the water permeability of the PET/ PGA graft will be dramatically lowered. Also, it is possible that the graft could lose impermeability when degraded or if
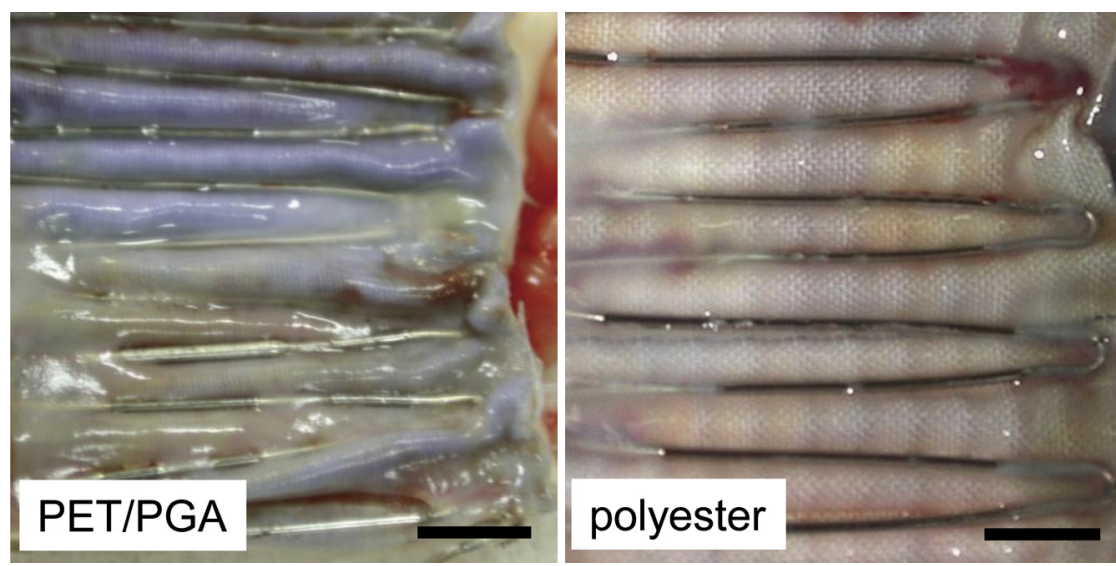

FIGURE 4. Macroscopic appearance of the luminal surface of the 2 grafts at 2 months after implantation (scale bar 5 mm). PET/PGA, Polyethylene terephthalate/polyglycolic acid. 

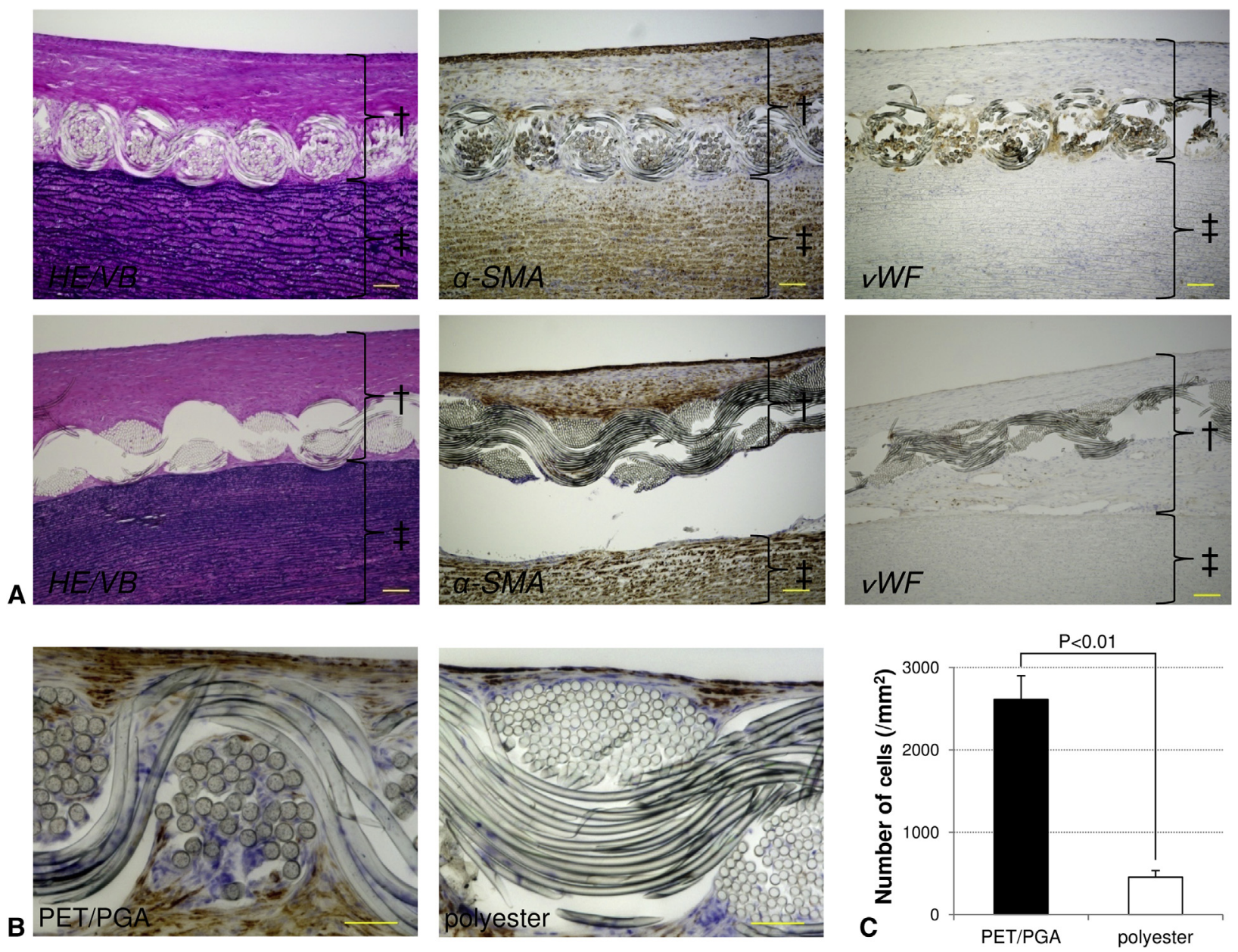

FIGURE 5. A, Histologic evaluation of the explants at 2 months after implantation. Upper, Polyethylene terephthalate (PET)/polyglycolic acid (PGA) graft. Lower, Thin-walled woven polyester graft, stained with left, hematoxylin-eosin $(H E)$ and Victoria blue (VB), middle, $\alpha$-smooth muscle actin $(\alpha-S M A)$, and right, von Willebrand factor $(\nu W F)$ (original magnification, $\times 100$; scale bar, $100 \mu \mathrm{m})$. $\dagger$ Layer of the neointima that contains the graft. $\ddagger$ Native aortic wall. B, Highly magnified image of the graft in the explant with $\alpha$-SMA staining to show cell infiltration into the graft. Left, PET/PGA graft (original magnification, $\times 200$; scale bar, $100 \mu \mathrm{m}$ ). Right, Thin-walled woven polyester graft (original magnification, $\times 400$; scale bar, $50 \mu \mathrm{m}$ ). The luminal side is oriented to the upper side in every A and B figure. C, The cell counts, expressed as the mean number of cells $/ \mathrm{mm}^{2}$, in the graft.

alteration of the neocellularized tissue occurs, leading to negative effects on the aortic lesions.

The histologic assessment at 2 months after implantation demonstrated good cell affinity of the PET/PGA graft. Host cells had infiltrated into the space where the PGA component had degraded and had formed unified tissue with the native aortic wall. The graft was sandwiched between the multilayered $\alpha$-SMA-positive cells, and the residual PET fibers appeared to have been incorporated into the subintimal tissue of the aorta. This tissue-mediated tight connection between the graft scaffold and the aortic wall might have led to the significantly enhanced fixation between the graft and native aortic wall. As Major and colleagues, ${ }^{6}$ and others, ${ }^{4}$ have noted, the enhanced attachment between the implant and the aortic wall by biological integration could decrease the risk of migration or endoleak after
EVAR. We expect that the tissue-recruiting effect of the PET/PGA graft will be conducive to a complete seal at the landing zone. With a larger study of aneurysm models, we could have compared the frequency of endoleak itself between the PET/PGA and control groups.

Regarding the process and mechanism of tissue recruitment into TEVGs, little is known to date. Three classic hypotheses have been advocated for the method of neointimal formation on prosthetic vascular grafts: (1) pannus extension from the adjacent aortic wall across the suture lines, (2) ingrowth of microvessels from the perigraft tissue through the interstices of the graft, and (3) endothelial formation of circulating blood origin. ${ }^{16-18}$ After degradation of the PGA component, the PET/PGA graft will behave as a porous graft, in which the host cells recruited by way any of the mechanisms described 
interact with each other, resulting in accelerated tissue regeneration on the scaffold.

Regarding the trigger for tissue regeneration on TEVGs, Roh and colleagues ${ }^{19}$ reported the association of inflammation with TEVGs made with similar biodegradable polymers. We have inferred that the inflammation induced by PGA metabolites from the PET/PGA graft might play a major role in the process of accelerated cell recruitment. PGA is known to activate an inflammatory response after hydrolysis in a living body. ${ }^{20}$ Inflammation causes angiogenesis and tissue regeneration through a number of mediators such as cytokines and growth factors, which induce proliferation and migration of the vascular cells. ${ }^{21}$

The present study had some potential limitations. Endothelialization on vascular prostheses has been more frail in humans than in animal models. ${ }^{22}$ Although Shin'oka and colleagues $^{23}$ reported good organization of a TEVG made with similar materials in clinical settings after explantation from a pediatric patient, tissue regeneration could be impaired, in particular, in elderly patients with degenerative aortic aneurysms. ${ }^{24}$ We also need to identify the precise mechanism of tissue regeneration on the graft in a timecourse study. More importantly, we must verify product safety. Although all the materials used in the present study had received Food and Drug Administration clearance and TEVGs fabricated with similar materials have been already brought into clinical application, ${ }^{23}$ additional investigation of the clinical conditions and histopathologic examinations with large numbers and long follow-up is necessary, especially because the graft is likely to induce an inflammatory reaction. Nonetheless, the results from the present study could serve as a foundation for the development of next generation stent-grafts.

\section{CONCLUSIONS}

The PET/PGA stent-graft induced histologic integration with the native aortic wall by recruiting host cells into the graft scaffolds. Also, it adhered more firmly to the native arterial wall compared with the conventional stent-graft using a woven polyester graft. The present study is the first to demonstrate that the tissue-engineered stent-graft will form histologic continuity with the host aorta and enhance the fixation force after EVAR. This novel stent-graft could dramatically improve the postoperative results of EVAR by reducing the risk of migration and endoleaks.

We would like to acknowledge the excellent technical assistance of Shigeru Matsumi.

\section{References}

1. EVAR Trial Participants. Endovascular aneurysm repair versus open repair in patients with abdominal aortic aneurysm (EVAR trial 1): randomized controlled trial. Lancet. 2005;365:2179-86.
2. Blankensteijn JD. Two-year outcomes after conventional or endovascular repair of abdominal aortic aneurysms. N Engl J Med. 2005;352:2398-405.

3. Ohki T, Veith FJ, Shaw P, Lipsitz E, Suggs WD, Wain RA, et al. Increasing incidence of midterm and long-term complications after EVAR of abdominal aortic aneurysms: a note of caution based on a 9 year experience. Ann Surg. 2001;234: 323-35.

4. Malina M, Brunkwall J. Endovascular healing is inadequate for fixation of Dacron stent-graft in human aortoiliac vessels. Eur J Vasc Endovasc Surg. 2001;19:5-11.

5. McArthur C, Teodorescu V, Eisen L, Morrissey N, Faries P, Hollier L, et al. Histopathological analysis of endovascular stent grafts from patients with aortic an eurysms: does healing occur? J Vasc Surg. 2001;33:733-8.

6. Major A, Guidoin R, Soulez G, Gaboury LA, Cloutier G, Sapoval M, et al Implant degradation and poor healing after endovascular repair of abdominal aortic aneurysms: AN analysis of explanted stent-grafts. J Endovasc Ther 2006; 13:457-67

7. Zarins CK, Bloch DA, Crabtree T, Matsumoto AH, White RA, Fogarty TJ, et al. Stent graft migration after endovascular aneurysm repair: importance of proximal fixation. J Vasc Surg. 2003;38:1264-72.

8. Fulton JJ, Farber MA, Sanchez LA, Godshall CJ, Martson WA, Mendes R, et al. Effect of challenging neck anatomy on midterm migration rates in AneuRx endografts. J Vasc Surg. 2006;44:932-7.

9. Abbruzzese TA, Kwolek CJ, Brewster DC, Chung TK, Kang J, Conrad MF, et al. Outcomes following endovascular abdominal aortic aneurysm repair (EVAR): an anatomic and device-specific analysis. J Vasc Surg. 2008;48:19-28.

10. Langer R, Vacanti JP. Tissue engineering. Science. 1993;260:920-6.

11. Kaushal S, Amiel GE, Guleserian KJ, Shapira OM, Perry T, Sutherland FW, et al. Functional small-diameter neovessels created using endothelial progenitor cells expanded ex vivo. Nat Med. 2001;7:1035-40.

12. Iwai T, Sawa Y, Taketani S, Torikai K, Hirakawa K, Matsuda H. Novel tissueengineered biodegradable material for reconstruction of vascular wall. Ann Thorac Surg. 2005;80:1821-8.

13. Torikai K, Ichikawa H, Hirakawa K, Matsumiya G, Kuratani T, Iwai S, et al. A self-renewing, tissue-engineered vascular graft for arterial reconstruction. J Thorac Cardiovasc Surg. 2008;136:37-45.

14. Yokota T, Ichikawa H, Matsumiya G, Kuratani T, Sakaguchi T, Iwai S, et al. In situ tissue regeneration using a novel tissue-engineered, small-caliber vascular graft without cell seeding. J Thorac Cardiovasc Surg. 2008;136:900-7.

15. Clowes AW, Kirkman TR, Reidy MA. Mechanisms of arterial graft healing rapid transmural capillary ingrowth provides a source of intimal endothelium and smooth muscle in porous PTFE prostheses. Am J Pathol. 1986;123: 220-30.

16. Wesolowski SA, Sauvage LR. Comparison of the fates of Orlon mesh prosthetic replacement of the thoracic aorta and aortic bifurcation. Ann Surg. 1956;143: $65-72$.

17. Stump MM, Jordan GL Jr, Debakey ME, Halpert B. Endothelium grown from circulating blood on isolated intravascular Dacron hub. Am J Pathol. 1963;43: $361-7$.

18. Kouchi Y, Onuki Y, Wu MH, Shi Q, Ghali R, Wechezak AR, et al. Apparent blood stream origin of endothelial and smooth muscle cells in the neointima of long, impervious carotid-femoral grafts in the dog. Ann Vasc Surg. 1998;12:46-54.

19. Roh JD, Sawh-Martinez R, Brennan MP, Jay SM, Devine L, Rao DA, et al. Tis sue-engineered vascular grafts transform into mature blood vessels via an inflammation-mediated process of vascular remodeling. Proc Natl Acad Sci U S A. 2010;107:4669-74.

20. Ceonzo K, Gaynor A, Shaffer L, Kojima K, Vacanti CA, Stahl GL. Polyglycolic acid induced inflammation: role of hydrolysis and resulting complement activation1. Tissue Eng. 2006;12:301-8.

21. Imhof BA, Aurrand-Lions M. Angiogenesis and inflammation face off. Nat Med 2006;12:171-2.

22. Zilla P, Bezuidenhout D, Human P. Prosthetic vascular grafts: wrong models, wrong questions and no healing. Biomaterials. 2007;28:5009-27.

23. Shin'oka T, Matsumura G, Hibino N, Naito Y, Watanabe M, Konuma T, et al. Midterm clinical result of tissue engineered vascular auto-grafts seeded with autologous bone marrow cells. J Thorac Cardiovasc Surg. 2005;129:1330-8.

24. Scheubel RJ, Zorn H, Silber RE, Kuss O, Morawietz H, Holtz J, et al. Agedependent depression in circulating endothelial progenitor cells in patients undergoing coronary artery bypass grafting FREE. J Am Coll Cardiol. 2003;42: 2073-80. 